\title{
Design and Implementation of Smart Helmet and Intelligent Bike System
}

\author{
R Karthik, K Jyothi, B Annapurna, B. Anusha, V Rajitha
}

\begin{abstract}
A smart helmet that covers and protects the head from any damage in driving a two-wheeler vehicle. The main aim of our project is to provide safety for a rider and to make life of citizens more secure while driving a vehicle. The alcohol sensor is used to detect the alcohol content in riders breath. If rider is in drunk state, without wearing the helmet the bike will not start. In this situation, the rider should have to wear the helmet then only the rider can start the bike. Zigbee module acts as transceiver to communicate between the sensors and control devices. The respective person of registered number can know the details whether the rider was drunk or not. The main advantage is to avoid the two-wheeler accidents and drunk drive cases. This project mainly focus on wearing of helmet or not.

Keywords :Smart helmet, Intelligent bike system, Arduino.
\end{abstract}

\section{INTRODUCTION}

Present days many people are using the two-wheeler vehicles, especially the teenagers are more interested in driving the bike and they are not following the proper rules and they are facing many road accidents. The people are consuming alcohol and driving the bike. This may leads to road accidents and we may lose our lives. To overcome these problems we are developed a system to reduce the road accidents. Our project consists of two units: helmet unit and bike unit. The Arduino Uno and Zigbee module are used for communication between the sensors and other devices. In bike unit, the GSM is used to send the message to the registered number and ADXL 345 accelerometer is used for fall detection. The relay acts as a switching device to start or stop the vehicle. Zigbee concept is used for signal transmission between helmet and bike unit.

\section{DESIGN AND IMPLEMENTATION}

\section{A. Block diagram}

From Fig 1 (a) and (b) represents the diagram of helmet

Revised Manuscript Received on December 30, 2019.

* Correspondence Author

R Karthik*, Department of Electronics and Communication Engineering, MLR Institute of Technology, Hyderabad, India. Email: karthik.r@mlrintitutions.ac.in

K Jyothi, Department of Electronics and Communication Engineering, MLR Institute of Technology, Hyderabad, India.

B Annapurna, Department of Electronics and Communication Engineering, MLR Institute of Technology, Hyderabad, India.

B Anusha, Department of Electronics and Communication Engineering, MLR Institute of Technology, Hyderabad, India.

V Rajitha, Department of Electronics and Communication Engineering, MLR Institute of Technology, Hyderabad, India.

(C) The Authors. Published by Blue Eyes Intelligence Engineering and Sciences Publication (BEIESP). This is an open access article under the CC BY-NC-ND license (http://creativecommons.org/licenses/by-nc-nd/4.0/) and bike unit. The helmet unit consists of Arduino Uno, Zigbee transmitter CC2530 module,MQ-3 alcohol sensor, Force Sensing Resistor,16x2 LCD display and power supply. In

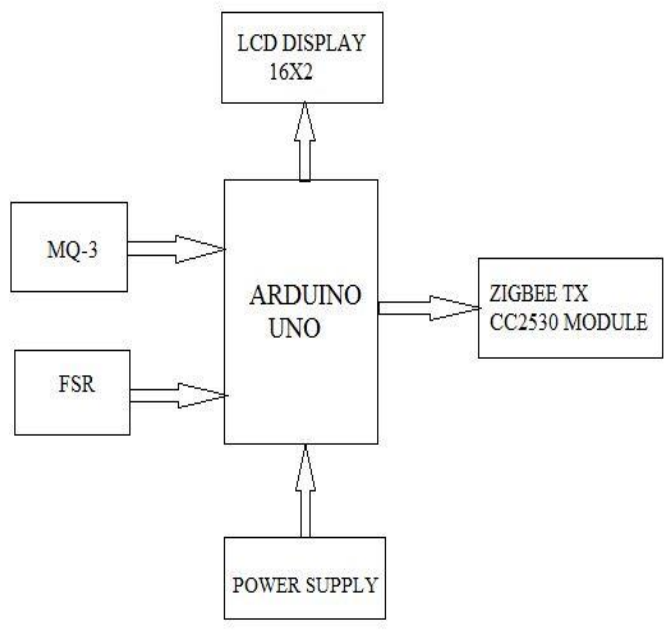

(a)

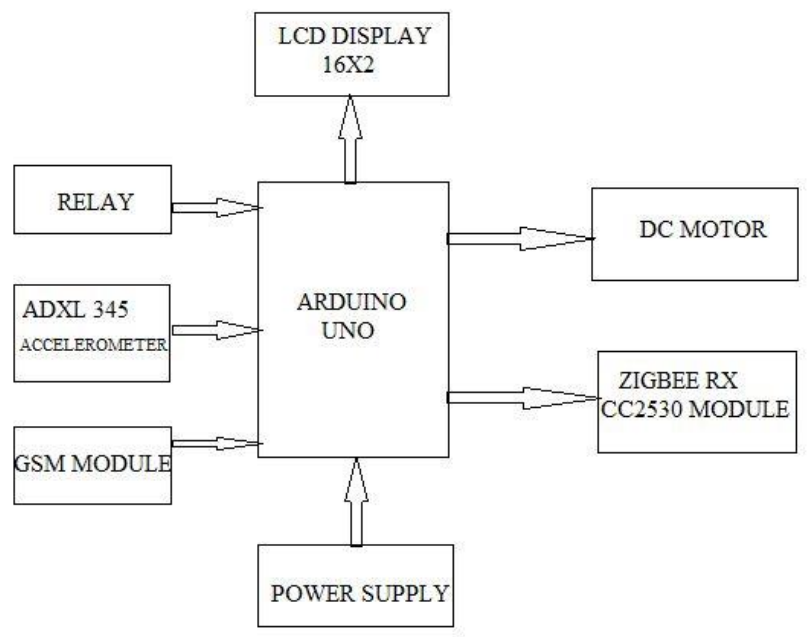

(b)

Fig. 1.Block diagram of (a) Helmet unit (b) Bike unit.

bike unit consists of Zigbee receiver CC2530 module, ADXL 345 accelerometer, GSM module, Relay, 16x2 LCD display, DC motor and power supply. These pins can read the signals from analog sensor like alcohol sensor, FSR sensor and convert it into a digital value that can read by the microprocessor. 


\section{Design and Implementation of Smart Helmet and Intelligent Bike System}

\section{B. Algorithm}

The algorithm that is used to solve the proposed system is as shown below:

1. Start

2. Switch ON the power supply in helmet unit and bike unit.

3. Initialize all the hardware modules.

4. Register the number in GSM module.

5. The registered number will display on LCD display.

6. It will send message to the registered number as "Reg" to the mobile phone.

7. If rider is not wear helmet, then it displays the message of "Helmet-No Wear" for the registered number.

8. If alcohol concentration present in rider breath then it displays the message as "Alc-ON" to the registered number.If person wear the helmet the motor will run i.e, the bike will start.

9. The readings will send to bike unit through Zigbee transmitter and receiver module.

\section{Principle of operation}

The working principle of our proposed system is explained below:

- Smart Helmet and Intelligent Bike System consists of two units namely helmet and bike unit.

- In helmet Unit, we are using two sensors that are MQ-3 Alcohol Sensor and Force Sensing Resistor(FSR). When we switch ON the power supply, the FSR or touch sensor. This information is transferred from helmet unit to bike unit through the Zigbee Transmitter and Receiver Module.

- In bike unit, we are using GSM Module is used to send the information or status of rider to the registered number. And we are using relay to start or stop the vehicle.

- The bike starts only when the rider wears the helmet and there is no alcohol content in rider' s breath. When a person is not wearing a helmet or rider consume alcohol, the bike remains in OFF state.

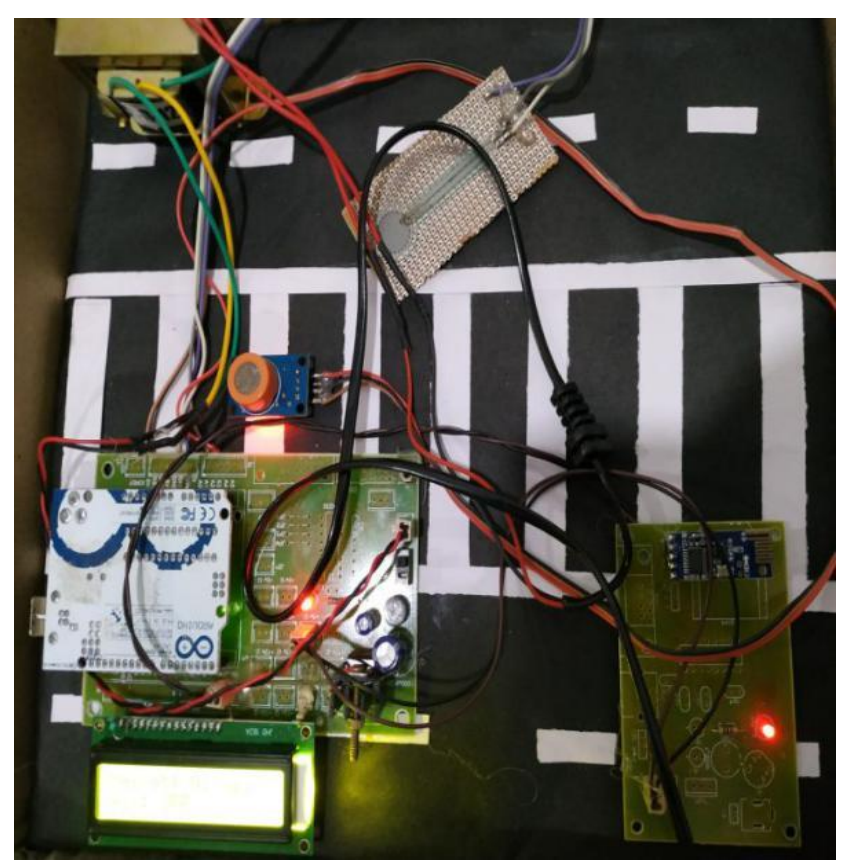

(a)

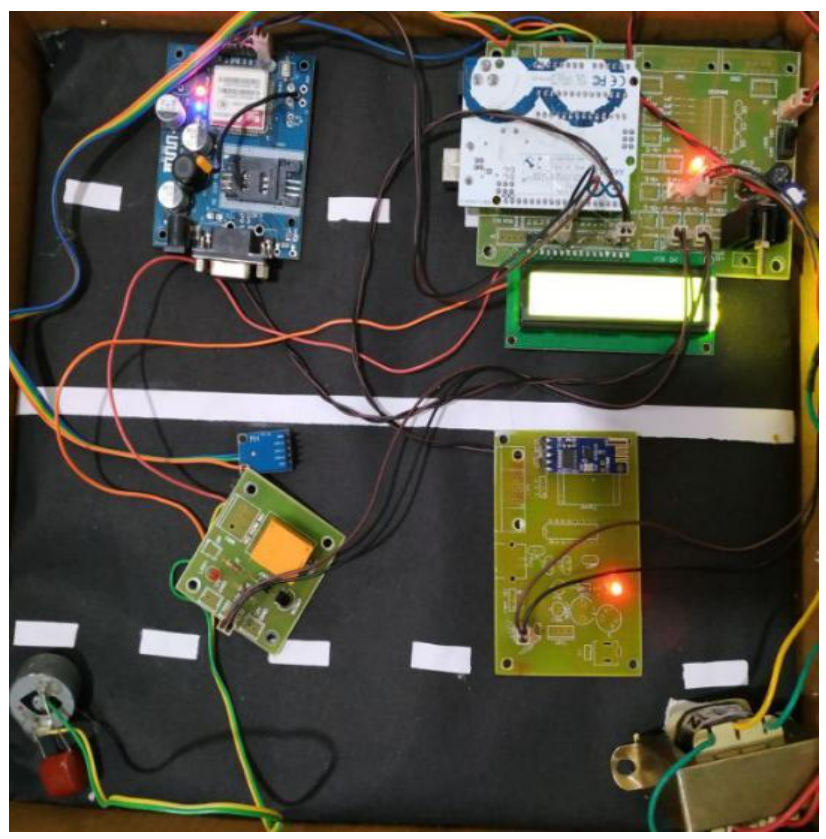

(b)

Fig. 2.Prototype result of (a) Helmet unit (b) Bike unit.

\section{RESULTS AND DISCUSSION}

The proposed and implemented prototypes are shown in Fig 2 (a) and (b). Figure 2 (a) shows the prototype model of helmet unit and Figure 2 (b) shows the prototype model of bike unit respectively. If alcohol concentration is present in human breath then it will display the message of "Alc-ON" and it sends the message to registered number which is shown in Fig 3 [5-12].

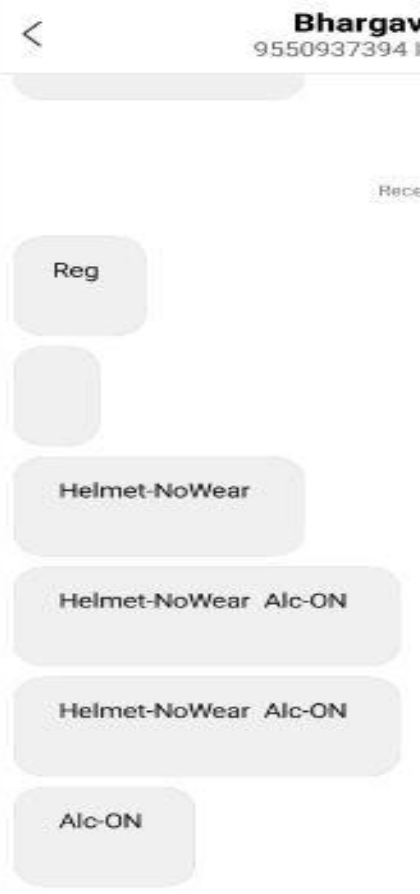

Fig. 3.Message to Registered Number . 
Advantages of the proposed system are as follows,

1. Less power consuming safety system.

2. Reduce the two-wheeler accidents.

3. Cost effective and easy to implement.

\section{CONCLUSION}

This paper presents the design of Smart Helmet and Intelligent Bike System. People can save their lives and avoid head injuries. In future the system can be implemented in four-wheeler vehicles by replacing the helmet with seat belt. We can implement the system using Solar energy.

\section{ACKNOWLEDGMENT}

The authors would like to thank the management of MLR Institute of Technology for their encouragement and support.

\section{REFERENCES}

1. SalunkeAkshay S," Smart Helmet \& Intelligent Bike System”, International Research Journal of Engineering and Technology (IRJET), Volume: 03, Issue: 05, PP.483-485, (2016).

2. Prajitha Prasad A," Smart Helmet \& Intelligent Bike System", International Journal of Current Engineering \& Scientific Research (IJCESR), Volume: 05, Issue: 05, PP.30-32, (2018).

3. B. Paulchamy," Desion of Smart Helmet and Bike Management System", Asian Journal of Applied Science and Technology (AJAST), Volume: 02, Issue: 02, PP.208-209, (2018).

4. BhosaleNilesh T," Smart Helmet \& Intelligent Bike System", Concepts Journal of Applied Research (CJAR), Volume: 02, Issue: 10, PP:02-04, (2017).

5. K Jyothi, R Karthik, Cloud Connectivity for Embedded Systems, International Journal of Advanced Trends in Computer Science and Engineering, Vol. 8, No. 3, pp. 731-733, (2019).

6. K Jyothi, R Karthik - Design and Implementation of Vehicle Over Speed Warning System, International Journal of Recent Technology and Engineering, Vol. 7, Issue 5, pp. 266-268, (2019).

7. Madhuri Baswa, R Karthik, P B Natarajan, K Jyothi, B Annapurna, "Patient Health Management System using e-Health Monitoring Architecture", IEEE International Conference on Intelligent Sustainable Systems 2017, Paladam, December 2017.

8. K Jyothi, Thottempudi Pardhu, R Karthik, T S Arulananth, "Design Methodology to check the Quality of the Image in a Mobile Environment - State of the Art", IEEE International Conference on Intelligent Sustainable Systems 2017, Paladam, December 2017.

9. P Haribabu, Sankit R Kassa, J Nagaraju, R Karthik, N Shirisha, M Anila, "Implementation of an Smart Waste Management system using IoT", IEEE International Conference on Intelligent Sustainable Systems 2017, Paladam, December 2017.

10. R Karthik, Dharma Reddy Tetali, Susmitha Valli Gogula, G Manisha Enhancement of Disciples Cognition levels using Bloom's Taxonomy in Data Mining, Journal of Advanced Research in Dynamical and Control Systems, Vol. 3S, pp. 1225-1237, (2018).

11. R Karthik, T Dharma Reddy, K H Vijaya Kumari, Susmitha Valli Gogula, Design And Development Of Intelligent Programmed Tool For Medical Diagnosis, International Journal of Pharmaceutical Research, Vol. 10, Issue 2, (2018).

12. R Karthik, K Jyothi, Novel Design of Full Adders using QCA Approach, International Journal of Advanced Trends in Computer Science and Engineering, Vol. 8, No. 3, pp. 501-506, (2019).

\section{AUTHORS PROFILE}

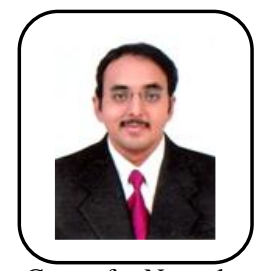

R. Karthik, received M. Tech degree from the Visvesvaraya Technological University, India and Ph.D degree from VIT University, India. He is currently the Professor at Department of Electronics and Communication, MLR Institute of Technology, Hyderabad. Earlier, he was working as a faculty member at VIT University, Vellore. His Ph. D thesis research work was carried out at one of the labs of Center for Nanoelectronics, Indian Institute of Technology - Bombay, India. He received best researcher award from VIT University for his contribution to Nanodielectrics in 2013 and 2014. His current area of research includes
Fabrication and Modeling of Nanoelectronic or Optoelectronic material based devices, Microwave Antennas, Medical Image Processing, Transformation in engineering education etc. He has published more than 80 research papers in reputed journals and conferences. He is one of the co-designer for developing a nano-size high performance capacitor in 2013.
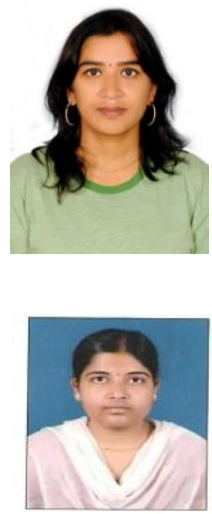

K Jyothi, received M.E degree from the Osmania University, India. Currently, she is working as Associate Professor in Department of Electronics and Communication Engineering, MLR Institute of Technology, Hyderabad. Her current area of research includes Innovation in Engineering Education. She got trained under IUCEE International Engineering Educator Certification Program.

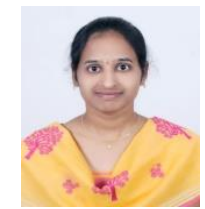

B Annapurna, receivedM.Tech degree from the MLR Institute of Technology, India. Currently, she is working as Assistant Professor in Department of Electronics and Communication Engineering, MLR Institute of Technology, Hyderabad. Her current area of research includes VLSI and Embedded Systems.

B Anusha, is currentlyworking as Assistant Professor in Department of Electronics and Communication Engineering, MLR Institute of Technology, Hyderabad. Her current area of research includes VLSI and Embedded Systems. 